\title{
Evaluation of the Clinical and Radiographic Outcomes of Pulpotomy in Primary Molars using Formocresol, CEM Cement and Sodium Hypochlorite $\mathbf{5 \%}$
}

\author{
Seyed Ebrahim Jabarifar', Seyedeh Zeinab Salehi² , Marjan Babadi \\ Borujeni $^{3}$
}

1Professor of Pediatric Dentistry, Isfahan University of Medical Sciences, Isfahan, Iran
${ }^{2}$ Postgraduate of Pediatric Dentistry, Isfahan University of Medical Sciences, Isfahan, Iran
${ }^{3}$ Postgraduate of Oral and Maxillofacial Radiology, Isfahan University of Medical Sciences, Isfahan, Iran

\begin{abstract}
Aim: This in vitro study was carried out to assess the clinical and radiographic success of pulpotomy in primary molars following the use of formocresol, sodium hypochlorite 5\% ( $\mathrm{NaCOl}$ ) and Calcium Enriched Mixture (CEM) cement. Materials and methods: This study was conducted on 108 primary molars of 5-8 year old children who referred to the pediatric dentistry, Isfahan faculty of dentistry. The selected teeth were equally distributed and randomly assigned to 3 groups of formocresol, sodium hypochlorite and CEM cement. After taking the initial radiography, standard pulpotomy was carried out by using formocresol, CEM cement and sodium hypochlorite 5\%, and the teeth were restored by Stainless Steel Crown (SSC). The clinical and radiographic evaluations were performed at 6 and 12-month follow-ups. Data was analyzed by chi-square and Relative Risk statistical tests. Results: After 6 months, all (100\%) of the pulpotomy medicaments were clinically successful. Also, there was no clinically significant difference between the results of primary molar pulpotomy in these 3 groups in the 1-year follow-up $(\mathrm{p}=0.129)$. There was not any significant difference between three groups in the first follow-up $(\mathrm{p}=0.364)$ and second follow-up ( $\mathrm{p}=0.100)$. Conclusion: There was no significant difference among the success rates of the pulpotomy medicaments used in primary molars. Moreover, the clinical and radiographic success rates of $\mathrm{NaOCl}$ $5 \%$ and CEM cement were comparable to those of formocresol.
\end{abstract}

Keywords: CEM Cement, Formocresol, Primary Dentition, Pulpotomy, Sodium Hypochlorite

\begin{abstract}
Introduction
Despite recent developments in preventive dentistry and increasing significance of preserving the teeth, the primary teeth are lost early due to decay or trauma. Early loss of primary dentition leads to irregularity in permanent dentition and psycho-social consequences $(1,2)$. To prevent these consequences, early intervention is required to cure inflammation and infection of primary teeth pulp.
\end{abstract}

If inflammation is limited to the coronal pulp and the root pulp tissue is healthy, pulpotomy will be the treatment of choice (3). Pulpotomy of primary dentition is defined as a clinical process of removing the coronal inflamed pulp to maintain the vitality and function of the root pulp (4).

Having removed the coronal inflamed pulp, the remaining root pulp needs to be covered with a pulp medicament which is ideally life-compatible and bactericidal, capable of creating biological seal and inducing hard tissue formation (5). To this end, various medicaments have been introduced.

Calcium hydroxide was introduced by Herman in 1930 as a pulp medicament (6). The antibacterial property of $\mathrm{CaOH}_{2}$ is a favorable characteristic of this medicament. However, low stimulation of dentinalbridge formation and its long solubility cause micro-

This article is published under the terms of the Creative Commons Attribution License 4.0

Author(s) retain the copyright of this article. Publication rights with Alkhaer Publications.

Published at: http://www.ijsciences.com/pub/issue/2015-04/

Article Number: V420150408; Online ISSN: 2305-3925; Print ISSN: 2410-4477 
leakage and tunnel defects, which consequently lead to inducing internal resorption and losing the teeth (1).

Formocresol (FC) was first used for pulpotomy by Sweat in 1930 (5). Despite the differing views, FC has been considered as gold standard in primary dentition pulpotomy over the past 100 years (5). The formaldehyde existing in FC was introduced as a carcinogen agent in 2004 (6), and application of FC in pulpotomy has been challenged over the past 20 years. $(5,7)$

Ferric sulphate was introduced as a substitute madicament for formocresol in 1991 (4). In spite of the clinical success $(81-97 \%)$, this material has disadvantages like severe inflammatory root pulp tissue changes, internal resorption and periapical radiolucency $(4,7)$.

Mineral Trioxide Aggregator (MTA) was proposed into dentistry in 1993, its good physical, chemical and biological properties were documented afterward (8). Moreover, by increasing $\mathrm{PH}$ in the connective tissue, MTA enhances its antimicrobial activity $(8,9$, 10). Despite the great characteristics of MTA, it has disadvantages such as unpredictable antimicrobial activity, difficult application, long hardening time and high costs (9). Recently, a new cement called Calcium Enriched Mixture (CEM) has been introduced in 2008, which has more appropriate properties like less function time, simpler application, better color and chemical features, better sealing ability, low cement thickness, high flow and low cost, compared to MTA $(2,10)$. In spite of similar PH and different compounds than MTA, CEM has similar clinical success to that of MTA $(9,10)$.

Sodium hypochlorite is a promising substitute medicament for pulpotomy, which has been used as a washing material for root canal treatment in permanent dentition since 1920 (4). This medicament has good antibacterial property with no definite stimulation of the pulp $(4,11)$. Other useful properties of this medicament include life-compatibility and homeostatic activity. It dissolves the surface necrosis of pulp tissue, but has no effect on the deeper healthy pulp $(4,11)$. In few studies, $\mathrm{NaOCl} 5 \%$ has been used for pulpotomy of primary dentition since 2006 and has had favorable results compared to ferric sulphate $(3,4)$.

In this randomized clinical trial study, the clinical and radiographic success and failure rates of pulpotomy of primary molars treated with formocresol, CEM cement and sodium hypochlorite $5 \%$ were evaluated in 6 and 12-month periods.

\section{Materials and methods}

This randomized clinical trial study was approved by the ethical committee of Isfahan University of Medical Sciences (grant no: 391363). The administration method, possible outcomes, advantages compared to disadvantages, and compensation method were explained to the children's parents,and consent forms were prepared before any intervention. Total number of 108 primary molars in 5-8 year-old healthy children from both genders, who referred to the pediatric dentistry of Isfahan faculty of dentistry, were selected for pulpotomy.

The inclusion criteria of the dentition were as follows:

1. All primary molars must be exposed due to carries and their pulps have to be alive.

2. In radiographic analysis, dentitions must not have any internal or external resorption,furcation lesion, periapical lesions, periodontal involvement and any pathologic sign in the root pulp. Also, the remaining root length must be higher than 2.3 in the radiography than the initial length.

3. The teeth must not have mobility, swelling, sinus tract and canal infection.

4. All dentitions must be restorable with posterior Stainless Steel Crown (SSC).

The radiographies were first prepared by ultra-speed film size (Eastman Kodak.Co, Rochester, NY, USA), which was fixed in the mouth by a film holder using an intra-oral radiography machine (Helsinki, Finland), $8 \mathrm{~mA}, 70 \mathrm{kvp}$ and $0.25 \mathrm{~s}$. The patients put on lead collar to protect the thyroid.

The dentitions were divided into formocresol, sodium hypochlorite 5\% and CEM cement groups according to the random number table.

In all groups after injecting lidocaine $2 \%$ and epinephrine 1/10000 (Pakhsh-Iran Darou) as local anesthesia, the carries was removed by a high speed diamond fissure bur no 330 and water-driven handpiece (NSK-Japan). After removing the pulp chamber roof, the coronal pulp tissue was removed by a round carbide bur size 0.25 and a low-speed handpiece (NSK-Japan). The initial homeostasis of coronal pulp occurred by using a cotton saturated with normal saline (Neoliter-Iran) for 5 minutes to ensure the healthiness of the pulp.

In the first group, formocresol-saturated cotton (Sultan Chemical, Englewood, NJ, USA) 1.5\%was diluted, and in the second group, the cotton moistened with $\mathrm{NaOCl} 5 \%$ ( The Clorox Co, Oakland, CA, USA) was put in the pulp chamber for 5 minutes in order to perform fixation. In both groups, if bleeding was continued, the tooth would be excluded from the study. Having ensured the pulp tissue fixation, $2 \mathrm{~mm}$ Zonalin(Kemdent-Sweden) was 
placed on the pulp chamber floor. After one week, the tooth was prepared for Stainless Steel Crown (SSC) (3M-USA) using Zinc polycarboxylate cement (poly-F, plus-Germany).

In the third group, the CEM cement powder and liquid (Bionique Dent-Iran) were mixed according to the manufactures instructions and put in the pulp chamber. Then, the same as previous groups, $2 \mathrm{~mm}$ thick Zonalin (Kemdent-Sweden) was applied. In the next session (after one day), the temporary filling was removed and after the cement was hardened, the 2mm-thick Zonalin (Kemdent-Sweden) was placed on the hardened cement. After one week, the tooth was prepared for SSC (Paul, MN, USA, 3M/ESPE,st.)using Zinc polycarboxylate cement (poly-F, plus-Germany).

The clinical and radiographic evaluation was performed at 6 and 12-month follow-ups. The clinical success was examined in the absence of spontaneous pain, mobility, swelling, fistula, gum inflammation (pain, redness and bleeding around the teeth or SSC) and in the case of healthy SSC. Also, the radiographic success was evaluated by a blind pediatric dentists and a blind radiologist in case there were no internal or external resorption and inter-root bone damage, respectively (It should be noted that the radiographies were performed as the same condition as the initial radiography).

Data were analyzed by SPSS software, version 18 (Apache software, Forest Hill, MD,USA) using chisquare and Relative Risk tests.

\section{Results}

Total number of 108 primary molars (66 primary first molars and 42 primary second molars) from 64 children (32 males and 32 females) were randomly divided into three groups of formocresol $(n=36), \mathrm{NaOCl}(\mathrm{n}=36)$ and CEM cement $(n=36)$. In the first group, 3 teeth and in the second group, 2 teeth were excluded from the study due to pulp bleeding. In the first follow-up (after 6 months), 93\% of the children (60 out of 64 children) with 90 pulpotomized primary molars referred(formocresol=30, $\mathrm{NaOCl}=30$ and $\mathrm{CEM}=30$ ) and underwent clinical and radiographic evaluation. In formocresol and $\mathrm{NaOCl}$ groups, from 30 teeth evaluated in the first follow-up, there were 18 primary first molars and 12 primary second molars. In the CEM group, however, 21 primary first molars and 9 primary second molars were assessed.

In the second follow-up (after 12 months), all children participated in the first follow-up referred again and underwent clinical and radiographic evaluation(Table 1).
In the first follow-up, all pulpotomized dentitions were clinically successful and no signs of failure were observed (Table 2).

In the second follow-up, all pulpotomized dentitions in formocresol and CEM groups were clinically successful and no sign of failure was reported. In $\mathrm{NaOCl}$ group, the inflammatory changes around SSC were observed in 2 teeth, but other teeth did not show any sign of pulpotomy failure (Table 2).

In the first follow-up, all pulpotomized teeth in formocresol and CEM groups were successful in terms of radiography and radiographic pathological changes were not observed. In $\mathrm{NaOCl}$ group, the radiographic changes were seen as widening of PDL space in furcation region in one tooth, but other teeth had no lesion (Table 2).

In the second follow-up, there were radiographic changes in the furcation area as widening of PDL in one tooth, but the other teeth had no lesion (Table 2).

No significant change was observed in terms of clinical success among these three groups in the second follow-up $(\mathrm{p}=0.129)$.

No significant change was reported in terms of clinical success between the findings of primary molar pulpotomy among the three groups in the first follow-up $(\mathrm{p}=0.364)$ and second follow-up $(\mathrm{p}=0.100)$.

\section{Discussion}

Therapeutic pulpotomy is applied to remove inflamed coronary pulp tissue in order to maintain the vitality and function of the pulp (4). Having removed the infected coronary pulp, the remaining pulp of the root needs to be covered with a medicament that is ideally biocompatible and bactericidal, capable to create biological seal and is capable to induce hard tissue formation (5).

The present randomized clinical trial study was conducted to analyze the success rate of primary molar pulpotomy by using diluted formocresol 1.5, sodium hypochlorite 5\%, and CEM cement.

Based on the findings of this study, no significant difference was observed between the clinical and radiographic findings primary molars pulpotomy using formocresol, sodium hypochlorite and CEM cement in the 6-month and 12-month follow-ups.

The highest rate of therapeutic failure in the present study was reported for furcation involvement, as widening of PDL space, which is different than the findings of previous studies. In most of previous studies, internal root resorption has been reported as the main cause of treatment failure $(6,10)$. In the present study, no internal resorption was observed in 
the teeth. This can be attributed to the application of lower concentrations of medicaments with lower $\mathrm{PH}$ than the medicaments used in other studies.

Formocresol is the gold standard medicament used for pulpotomy of primary dentition. The findings of the present study showed that the clinical success rate of this material was $100 \%$ in the 6 and 12-month follow-ups and its radiographic success rates in the 6 and 12-month follow-ups were $100 \%$ and $96 \%$, respectively. The results of this study are compatible with the findings of Ruby et al (6) in terms of clinical evaluation. In Ruby et al's study, the effect of formocresol and sodium hypochlorite was analyzed in the pulpotomy of 65 primary molars and findings indicated clinical success for all the teeth that were clinically reevaluated after 6 and 12 months. The radiographic success of formocresol treatment in the 6 and 12-month follow-ups were $84 \%$ and $90 \%$, respectively. They also reported that in the formocresol group, the internal root resorption was the only cause of treatment failure for primary molar pulpotomy (4 teeth in the 6-month follow-up and one tooth in the 12-month follow-up). In Ruby et al's study, the higher success rate of treatment in the 12month radiographic evaluation compared to 6-month evaluation was due to the change in the number of evaluated teeth in the follow-ups (in the 6 and 12month follow-ups, 25 and 10 teeth were evaluated in formocresol group, respectively).Based on the results of the present study, only 1 tooth had furcation involvement in the 12-month evaluation and no internal resorption was observed in the teeth.

In another study conducted by AL-Mutairi and Bawazir (11), the success rate for the pulpotomy of primary molars (82 teeth) was analyzed by formocresol $20 \%$ and sodium hypochlorite $5 \%$ in the 3,6 , and 12-month follow-ups. The findings of their clinical evaluation revealed the success rates of $100 \%, 95 \%$ and $92.1 \%$ in the 3, 6, and 12-month periods, respectively as well as the success rates of $100 \%, 95 \%$ and $86.8 \%$ in the 3, 6, and 12-month follow-ups in terms of radiographic evaluation, which are in line with the findings of present study.

According to the reports about the carcinogen property of the formaldehyde existing in formocresol, in recent years, there has been a lot of attention on a medicament that can have as same clinical and radiographic success formocresol with no harmful effects.

Sodium hypochlorite is a promising replacement for pulpotomy. It has proper antibacterial, biocompatible and homeostatic properties (4). In 2006, Vegas et al (3) used $\mathrm{NaOCl} 5 \%$ in order to pulpotomy of primary molars for the first time. They compared the clinical and radiographic results of primary molar pulpotomy by Ferric sulphate $15.5 \%$ and sodium hypochlorite $5 \%$. Their results showed that the clinical success rate of $\mathrm{NaOCl}$ was $100 \%$ in the 6 and 12 -month followups and the radiographic success rates were $91 \%$ and $79 \%$ in the 6 and 12-month follow-ups, respectively. They also reported higher success rate of pulpotomy by $\mathrm{NaOCl} 5 \%$ than Ferric sulphate $15.5 \%$.

According to the results of the present study, the clinical and radiographic success rates of pulpotomy by $\mathrm{NaOCl} 5 \%$ were $100 \%$ and $93.3 \%$, respectively in the 6-month follow-up and 96.6\% in the 12-month follow-up, which are in line with the findings of Vegas et al (3). In the present study in the 6-month follow-up, one tooth had furcation involvement and in the 12-month follow-up, two teeth had inflammation around SSC and one tooth had furcation involvement. However, in Vegas et al's study (3), internal root resorption was the only cause of treatment failure, which is in contrast with the results of present study in this regard. Moreover, the findings of Ruby et al (6) indicated $100 \%$ clinical success for pulpotomy in the 6 and 12-month followups in sodium hypochlorite group, which is in agreement with the findings of 6-month follow-up in the present study; however, in the 12-month followup in the present study, two teeth had inflammation around SSC, which was not observed in Ruby et al's study (6). The radiographic evaluation also showed that treatment success rates of sodium hypochlorite were $86 \%$ and $80 \%$ in the 6 and 12 -month followups. The findings of Ruby et al indicated that in sodium hypochlorite group, the failure causes of primary molar pulpotomy in the 6-month follow-up were internal root resorption (two teeth) and furcation involvement. However, in the 12-month follow-up, one tooth had internal root resorption and two teeth had furcation involvement. In the present study in the 6 and 12-month follow-ups, one tooth had furcation involvement and no internal resorption was observed.

Calcium Enriched Mixture (CEM cement) is mainly composed of $\mathrm{CaO}, \mathrm{SiO}_{2}, \mathrm{P}_{2} \mathrm{O}$ and $\mathrm{SO}_{3}$. It has easy application, antimicrobial property and excellent sealing ability and has recently been introduced as a pulp medicament for primary molar pulpotomy. Asgary et al (13) used this medicament for the first time for pulpotomy of primary molars with irreversible inflammation and concluded this medicament is able to prevention of internal root resorption favorably. Further, Tabarsi et al (2) analyzed the success rate of pulpotomy using MTA, CEM cement and calcium hydroxide and concluded that the success rate of pulpotomy was favorable and comparable in MTA and CEM cement groups based on the clinical and histological evaluations. They also reported that these two medicaments had higher success rate than calcium hydroxide. 
The findings of the present study indicated the clinical success rate of $100 \%$ for this medicament in the 6 and 12-month follow-ups and radiographic success rates of $100 \%$ and $96 \%$ in the 6 and 12 month follow-ups, which are in agreement with the results of Asgari (12) and Tabarsi (2). The results of this study indicated that the clinical and radiographic success rate of CEM cement was similar to that of formocresol; meanwhile, CEM cement lacks formaldehyde compounds too.

Furthermore, in a study conducted by Khorakian et al (13) on 102 primary second molars, the clinical and radiographic success rate of pulpotomy by using CEM cement was assessed in 6, 12 and 24-month follow-ups and the findings demonstrated the clinical success rate of $100 \%$ and radiographic success rates of $95.9 \%$ (treatment failure of 2 cases), $97.9 \%$ (treatment failure of one case) and $90 \%$ (treatment failure of 4 cases), respectively. Internal root resorption was the cause of treatment failure. The results of this study confirm our findings in terms of clinical evaluation. However, in this study no internal resorption was observed in the teeth in CEM cement group and furcation involvement was seen after 12 months merely in one tooth.

\section{Conclusion}

The results of this study revealed no significant difference between the results of primary molar pulpotomy using CEM cement and $\mathrm{NaOCl} 5 \%$ and formocresol. CEM cement and $\mathrm{NaOCl} 5 \%$ can be used for pulpotomy as a substitute for formocresol.

\section{Recommendations}

This study only carried out the clinical and radiographic assessment of CEM cement, $\mathrm{NaOCl} 5 \%$ and formocresol. Future studies are recommended to perform analyzing the histological aspect of treatment and hard tissue formation in a larger population and a longer follow-up in addition to clinical and radiographic evaluation.

\section{References}

I. Ghajari MF, Jeddi TA, Iri S, Asgary S. Direct pulpcapping with calcium enriched mixture in primary molar teeth: a randomized clinical trial. IEJ 2010;5(1):27

II. Tabarsi B, Parirokh M, Eghbal M, Haghdoost A, Torabzadeh H, Asgary S. A comparative study of dental pulp response to several pulpotomy agents. Int Endod J. 2010;43(7):565-71. http://dx.doi.org/10.1111/j.1365 2591.2010.01711.x

III. Vargas KG, Packham B, Lowman D. Preliminary evaluation of sodium hypochlorite for pulpotomies in primary molars. Pediarr Dent 2006;28(6).

IV. Vostatek SF, Kanellis MJ, Weber-Gasparoni K, Gregorsok RL. Sodium hypochlorite pulpotomies in primary teeth: a retrospective assessment. Pediarr Dent

V. 2011;33(4).

VI. Peng L, Ye L, Tan H, Zhou X. Evaluation of the formocresol versus mineral trioxide aggregate primary molar pulpotomy: a meta-analysis. Oral Surg Oral Med Oral Pathol Oral Radiol endod 2006:102(6):e40-e4. http://dx.doi.org/10.1016/j.tripleo.2006.05.017

VII. Ruby JD, Cox CF, Mitchell SC, Makhija S, CHOMPU-INWAI P, Jackson J. A randomized study of sodium hypochlorite versus formocresol pulpotomy in primary molar teeth. Int J Paediatr Dent 2013;23(2):145-52. http://dx.doi.org/10.1111/j.1365263x.2012.01237.x

VIII. Havale R, Anegundi RT, Indushekar K, Sudha P. Clinical and Radiographic Evaluation of Pulpotomies In Primary Molars With Formocresol, Glutaraldehyde and Ferric Sulphate. Oral Health Dent Manag. 2013;12(1):24-31.

IX. Santos A, Moraes J, Araújo E, Yukimitu K, Valério Filho W. Physico chemical properties of MTA and a novel experimental cement. Int Endod J. 2005;38(7):443-7. http://dx.doi.org/10.1111/j.1365 2591.2005.00963.x

X. Asgary S, Ehsani S. Permanent molar pulpotomy with a new endodontic cement: A case series. J Conserv Dent 2009;12(1):31. http://dx.doi.org/10.4103/09720707.53340

XI. Nosrat A, Peimani A, Asgary S. A preliminary report on histological outcome of pulpotomy with endodontic biomaterials vs calcium hydroxide. Restor Dent Endod. 2013;38(4):227-33.

http://dx.doi.org/10.5395/rde.2013.38.4.227

XII. Al-Mutairi M, Bawazir O. Sodium Hypochlorite versus Formocresol in primary molars pulpotomies: a randomized clinical trial. Eur J Paediatr Dent. 2013;14(1):33-6.

XIII. Asgary, Saeed. Calcium-enriched mixture pulpotomy of a human permanent molar with irreversible pulpitis and condensing apical periodontitis. J Conserv Dent .2011; 14(1): 90. http://dx.doi.org/10.4103/0972-0707.80733

XIV. Khorakian F, Mazhari F, Asgary S, Sahebnasagh M, Kaseb AA, Movahhed T, et al. Two-year outcomes of electrosurgery and calcium-enriched mixture pulpotomy in primary teeth: a randomised clinical trial. Eur Arch Paediatr Dent. 2014:1-6. http://dx.doi.org/10.1007/s40368-013-0102-z 
Evaluation of the Clinical and Radiographic Outcomes of Pulpotomy in Primary Molars using Formocresol, CEM Cement and Sodium Hypochlorite 5\%

Table 1. Distribution of the dentition at the beginning of the treatment and in the 6 and 12-month follow-ups

\begin{tabular}{|c|c|c|c|c|c|c|c|c|c|}
\hline & Sta & f treatm & & 6-m & evaluatios & & $12-$ & valuatio & \\
\hline & Gro & & & Grol & & & Gro & & \\
\hline Treatment & FC & $\mathrm{NaOCl}$ & $\begin{array}{l}\text { CE } \\
\mathbf{M}\end{array}$ & FC & $\mathrm{NaOCl}$ & CEM & FC & $\mathrm{NaOCl}$ & CEM \\
\hline First molar & 21 & 21 & 24 & 18 & 18 & 21 & 18 & 18 & 21 \\
\hline Second mola & & & & & & & & & \\
\hline & 15 & 15 & 12 & 12 & 12 & 9 & 12 & 12 & 9 \\
\hline Total & 36 & 36 & 36 & 30 & 30 & 30 & 30 & 30 & 30 \\
\hline
\end{tabular}

Table 2. Results of pulpotomy using formocresol, sodium hypochlorite and CEM cement in 6 and 12-month follow-

\begin{tabular}{lllllll} 
& \multicolumn{3}{c}{ ups } & & \multicolumn{3}{c}{ Radiographic evaluation } \\
\cline { 2 - 6 } $\begin{array}{l}\text { Treatment } \\
\text { month }\end{array}$ & FC & NaOCl & CEM & FC & NaOCl & CEM \\
& & & & & & \\
\end{tabular}

\begin{tabular}{|c|c|c|c|c|c|c|c|}
\hline \multirow[t]{2}{*}{ Pain } & 6 & 0 & 0 & 0 & - & - & - \\
\hline & 12 & 0 & 0 & 0 & - & - & - \\
\hline \multirow[t]{2}{*}{ Swelling } & 6 & 0 & 0 & 0 & - & - & - \\
\hline & 12 & 0 & 0 & 0 & - & - & - \\
\hline \multirow[t]{2}{*}{ Mobility } & 6 & 0 & 0 & 0 & - & - & - \\
\hline & 12 & 0 & 0 & 0 & - & - & - \\
\hline \multirow[t]{2}{*}{ Inflammation } & 6 & 0 & 0 & 0 & - & - & - \\
\hline & 12 & 0 & 2 & 0 & - & - & - \\
\hline \multirow[t]{2}{*}{ Abscess $\mathbf{H}$} & 6 & 0 & 0 & 0 & - & - & - \\
\hline & 12 & 0 & 0 & 0 & - & - & - \\
\hline \multirow[t]{2}{*}{ External root resorption } & 6 & - & - & - & 0 & 0 & 0 \\
\hline & 12 & - & - & - & 0 & 0 & 0 \\
\hline \multirow[t]{2}{*}{ Internal root resorption } & 6 & - & - & - & 0 & 0 & 0 \\
\hline & 12 & - & - & - & 0 & 0 & 0 \\
\hline Furcation involvement & $\begin{array}{l}6 \\
12\end{array}$ & - & - & - & 0 & 1 & 0 \\
\hline
\end{tabular}

